\title{
Investigations into the Water Repellent Surface Near Layer in Concrete by Neutron Radiography
}

\author{
P. Zhang ${ }^{1}$, F. H. Wittmann ${ }^{1,2^{*}}$, T. J. Zhao ${ }^{1}$ and E. H. Lehmann ${ }^{3}$ \\ ${ }^{1}$ Qingdao Technological University, Qingdao, China \\ ${ }^{2}$ Aedificat Institute Freiburg, Freiburg, Germany \\ ${ }^{3}$ Paul-Scherrer-Institut, Villigen, Switzerland \\ ${ }^{*}$ Corresponding author: F. H. Wittmann, e-mail: wittmann@aedificat.de
}

\begin{abstract}
By impregnation of concrete with a water repellent compound such as silane, a water repellent surface layer can be established. Due to this surface impregnation capillary absorption of water and aqueous salt solutions can be significantly reduced. The aim of this protective surface treatment is in many cases to obtain better frost resistance and to reduce chloride penetration. Water vapor can still transgress the impregnated layer in and out of concrete. In this contribution experimental results to visualize the width and the water content within the water repellent surface layer are described. The water distribution was determined quantitatively by neutron radiography. The results obtained allow us to explain earlier findings, which indicated that an efficient chloride barrier can be established by deep impregnation only. In a water repellent layer with a thickness lower than $6 \mathrm{~mm}$ there remains enough water which allows reduced migration of chloride into the pore space of the material. The requirements of published recommendations are herewith supported and justified.
\end{abstract}

Keywords: Surface Impregnation; Silane; Water repellent concrete; Neutron radiography. 


\section{Introduction}

Carbonation and chloride penetration into reinforced concrete are often the main reason for necessary early repair measures and too short service life of buildings and structures. Chloride is in many cases transported into the pore space of concrete by convection when salt solutions, such as seawater or water contaminated with deicing salt, are absorbed by capillary action. Once the chloride is transported into the pore space of concrete by quick capillary action it may further migrate slowly by diffusion to reach finally the steel reinforcement. If a critical concentration of chloride is reached in the region around the steel reinforcement, corrosion may start. If the surface of concrete is impregnated with a water repellent substance such as linseed oil or silane, capillary absorption may become negligible. In practice it has been observed quite often, however, that chloride penetrated into surface impregnated concrete, although with reduced rate.

If a very thin surface layer is impregnated only, the water repellent effect may be obvious during visual inspection of a surface when water is splashed on it. But in practice in most cases an aqueous salt solution is in contact with the concrete surface for longer periods, may be days or even weeks. Experimental results have shown that a minimum thickness of the water repellent surface layer must be achieved to make sure that chloride cannot enter the pore space.

In this contribution the thickness of different water repellent layers shall be determined quantitatively by means of neutron radiography. If it can be proved that in thin water repellent layers there is still some liquid water available, chloride ions may migrate through the layer by diffusion, passing through still existing water bridges. In this case chloride penetration may be slowed down but it will not be prevented. It should also be studied, which minimum thickness of the water repellent layer is necessary to act as a real chloride barrier. Based on these data requirements for an efficient chloride barrier can be formulated or verified and reliable recommendations for practical applications can be formulated. This may be considered to be a reliable basis for quality control.

\section{Experimental}

\subsection{Preparation of Mortar Specimens}

In order to study the specific properties of a water repellent surface near zone in cement-based materials, mortar cubes with an edge length of $100 \mathrm{~mm}$ have been produced in steel forms. The water-cement ratio of the mortar for these test series was chosen to be 0.6 . Details of the composition of the mortar are given in Table 1. Ordinary Portland cement type 42.5 and river sand with a maximum grain size of $2.5 \mathrm{~mm}$ were used. The fresh mortar was covered with a plastic sheet after compaction and stored in the workshop for 24 hours. Then the steel forms were removed and the concrete cubes were stored in a humid room with $\mathrm{RH} \geq 95 \%$ and $\mathrm{T}=20 \pm 2{ }^{\circ} \mathrm{C}$ until they have reached an age of 28 days. The hardened mortar cubes were then cut into slices with a thickness of approximately $20 \mathrm{~mm}$ with a diamond saw. The slices with dimensions of $20 \times 100 \times 100 \mathrm{~mm}$ were further stored in the laboratory atmosphere, which has a relative humidity of approximately $60 \%$ and a room temperature of approximately $20^{\circ} \mathrm{C}$, for one week. Then the mortar slices were ready for impregnation with silane gel, i. e. liquid silane stiffened by addition of fine clay particles.

\subsection{Surface Impregnation}

The surface of the mortar slices, which was in contact with the bottom of the steel forms during casting, was selected for impregnation. This represents a formed surface in contrast to a finished surface. This formed surface was impregnated with silane gel (StoCryl HG200). Three different amounts of silane gel were carefully spread equally over the surface: $100 \mathrm{~g} / \mathrm{m}^{2}, 400 \mathrm{~g} / \mathrm{m}^{2}$ and $600 \mathrm{~g} / \mathrm{m}^{2}$. The differently treated samples were labeled with G100, G400 and G600. All three types of impregnated mortar specimens were then stored for four more weeks in the laboratory atmosphere to allow the penetrated silane to react fully to form a silicon resin film on the inner surface of the mortar and to reach hygral equilibrium with the laboratory atmosphere. By gravimetry it was checked if hygral equilibrium was achieved.

Table 1: Composition of the mortar, the mass of cement, sand and water is given as $\mathrm{kg} / \mathrm{m}^{3}$.

\begin{tabular}{|c|c|c|c|}
\hline W/C & Water & Cement & Sand \\
\hline 0.6 & 300 & 500 & 1650 \\
\hline
\end{tabular}




\subsection{Neutron Radiography}

Water repellent mortar specimens and untreated companion mortar specimens were then tested in the neutron radiographic facilities NEUTRA at Paul-Scherrer-Institute (PSI) in Villigen, Switzerland. The diameter of the neutron beam was $400 \mathrm{~mm}$ and the collimation ratio was 550 . The neutron flux during the tests was $5.1 \times 10^{6}$ $\mathrm{cm}^{-2} \mathrm{~s}^{-1} \mathrm{~mA}^{-1}$. More details on neutron radiography are described in the literature [1-3]. First, neutron images were taken on samples, which were in hygral equilibrium with the room atmosphere $\left(\mathrm{RH} \approx 60 \% ; \mathrm{T} \approx 20^{\circ} \mathrm{C}\right)$. Then silane impregnated and untreated samples were placed in water for three days. This period was sufficient to have the samples completely water saturated by capillary absorption. Neutron images were first taken from mortar specimens, which were in hygral equilibrium with the laboratory atmosphere (air dry). Then neutron images were taken from water saturated samples. Both, untreated and surface impregnated mortar samples in the water saturated state were investigated. From the neutron images the moisture distribution can be determined quantitatively.

\section{Results and Discussion}

\subsection{Neutron Transmission}

Neutron images of the three types of impregnated and water saturated mortar specimens are shown in Fig. 1. As the upper impregnated surface is of interest exclusively in this context, the upper half of the neutron images is shown in Fig. 1 only. It can be clearly seen with the naked eye that the neutron transmission is significantly higher in the outer impregnated layer. The thickness of the impregnated layer can be estimated already from the results shown in Fig. 1. The following average values of the thickness of the impregnated layer have been determined by visual inspection 2.0, 4.1, and $6.3 \mathrm{~mm}$ for samples G100, G400, and G600 respectively.

The darker area in Fig. 2 represents the surface near zone, which is impregnated with silicon resin. Enough hydrogen is fixed in silicon resin in $\mathrm{OH}$-groups and $\mathrm{CH}$-groups and this hydrogen is at the origin of scattering neutrons out of the neutron beam. This process leads to the darker surface zone, which can be observed in Fig. 2. The thickness of this zone corresponds to the thickness of the zone with reduced water content shown in Fig. 1. The technology to visualize the silicon resin films opens up new possibilities and it will be further developed in the future.

The neutron transmission of untreated and silane impregnated mortar specimens has been determined quantitatively. In Fig. 3 the transmission profiles as obtained on untreated specimens stored in the laboratory atmosphere and on water saturated samples are shown. As expected the neutron absorption of the water saturated specimens is much higher. The difference between the two lines shown in Fig. 2 is approximately constant, that means samples are homogeneously filled with water. In this case the water content of the air dry samples was $6.5 \mathrm{Vol} . \%$ and the water content of the saturated samples was $18.4 \mathrm{Vol}$. \%. As a consequence the distance between the two lines in Fig. 3 represents a homogeneous water content of 11.9 Vol. \%. From these data we can calculate that in the hydration products of the dry mortar there is approximately $4.1 \mathrm{Vol}$. \% of water chemically bound.

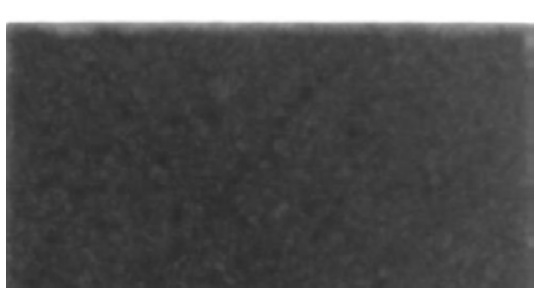

G100

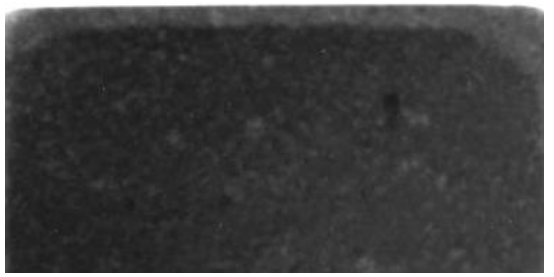

G400

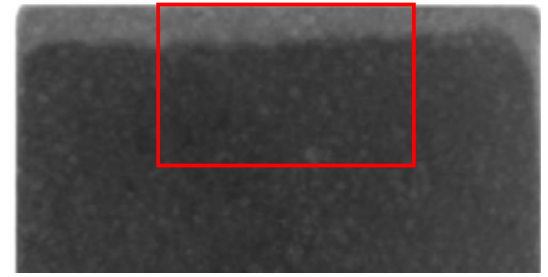

G600

Figure 1: Neutron images as obtained on the three types of water repellent surface impregnated and water saturated mortar specimens. The upper half of the neutron images taken on square slabs is shown only. 


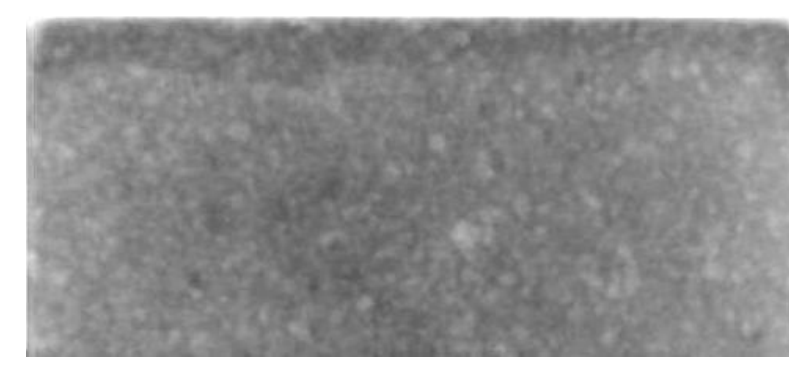

Figure 2: Neutron image of an air dry specimen after impregnation with $600 \mathrm{~g} / \mathrm{m}^{2}$ of silane gel (G600). In this case the silicon resin in the impregnated zone can be visualized.

The neutron transmission as determined on the three surface impregnated specimens G100, G400 and G600 are shown in Fig. 4. The transition of samples G100 in the bulk of the specimens is nearly constant but close to the impregnated surface transmission goes up. The influence of the silane impregnation in samples G100 can be observed until a depth of approximately $2 \mathrm{~mm}$. In the air dried specimen there is less water in the surface near zone. That means that a certain part of the pores which are filled by capillary condensation in untreated specimens are empty after water repellent treatment, because the walls of these pores are covered by a silicon resin film. Finer pores still contain

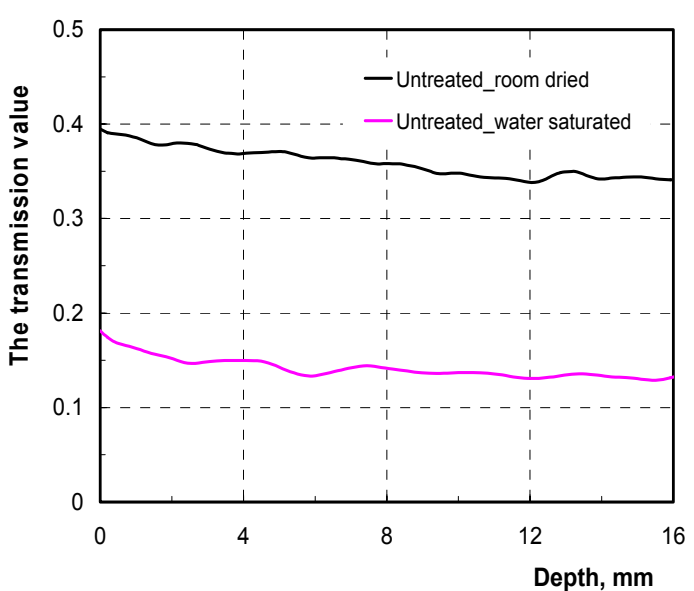

Figure 3: Neutron transmission as function of the distance from the surface, measured on untreated water saturated and untreated room dry samples.

capillary condensed water under the environmental relative humidity. It is quite obvious that the influence of the reduced water content on neutron transmission is much stronger than the influence of the silicon resin. Nevertheless for a quantitative analysis the contribution of the silicon resin has to be taken into consideration.

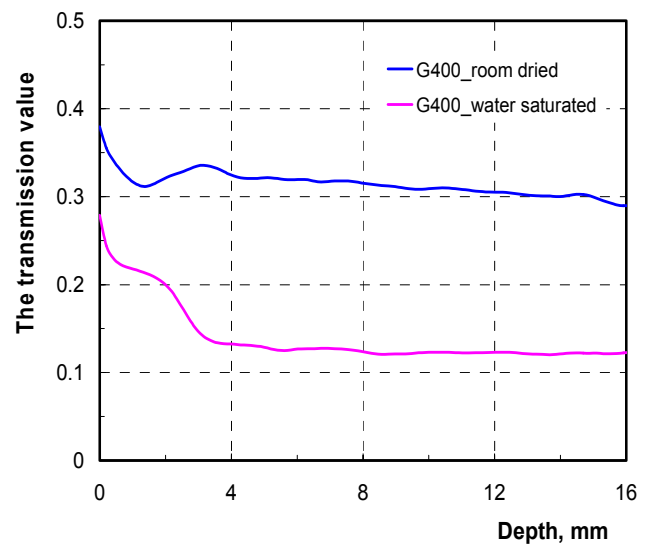

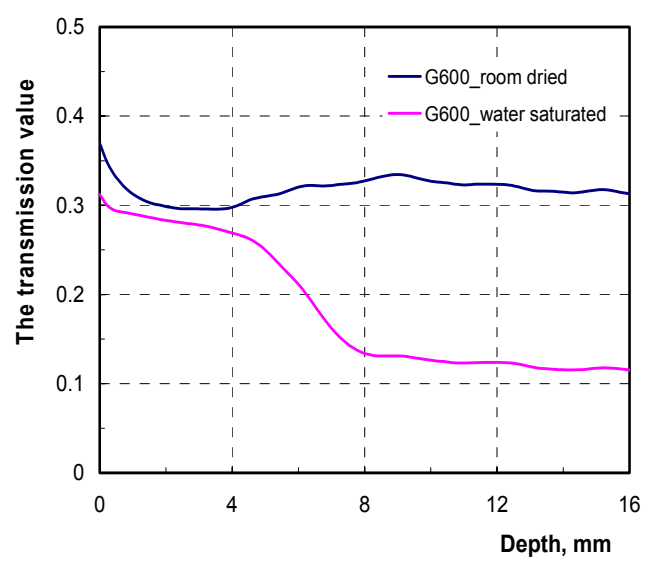

Figure 4: Transmission as measured on the neutron images of the three types of water saturated and room dry mortar specimens of G100, G400 and G600. 
The situation in samples G400 is similar but the influence of the water repellent layer reaches obviously deeper into the material, that means silane has penetrated deeper into the pore space. As expected the water content of the G600 specimens is strongly reduced in a surface near layer with a thickness of approximately $6 \mathrm{~mm}$. There is a small difference only between the transmission of the room dry and the water saturated specimens in the surface near impregnated zone. In specimens G600 the water content in the water saturated state approaches the water content of the room dried samples. Nearly no water has been taken up by capillary absorption. This situation can be considered to be a necessary requirement for the establishment of a reliable chloride barrier.

\subsection{Water Distribution}

The water distribution was calculated in the surface near zone as indicated with the rectangular frame shown in Fig. 1 (G600) from the neutron images obtained from water saturated specimens. Results are shown in Fig. 5. As expected the moisture content in the untreated specimen is essentially homogeneously distributed all over the volume. The observed slight decrease of water content close to the surface may be attributed to a small water loss during handling before taking the first neutron image.

On the surface impregnated specimens, however, the influence of the water repellent surface near zone can be observed clearly. As expected, the water content in the water repellent zone is signifi- cantly reduced. The width of the water repellent zone can also be observed quite clearly. In samples G100 a water repellent layer with a thickness of approximately $2 \mathrm{~mm}$ has been established. In samples G400 and G600 the thickness of the water repellent zone can be estimated to be approximately 4 and $6 \mathrm{~mm}$ respectively. What is most important, however, is the fact that in samples G100 and G400 the water content in the water repellent zone is certainly substantially reduced but still a certain amount of water can be observed in this region. In contrast in samples G600 a minimum amount of water can be detected only. From these results it can again be concluded that deep impregnation as in specimens G600 is necessary for an efficient chloride barrier. The remaining water in the impregnated specimens G100 and G400 may still transport a certain amount of dissolved chloride ions.

This observation is in good agreement with results of tests to check the efficiency of surface impregnation with respect to chloride penetration. If the water repellent zone is not thick enough the rate of chloride penetration is reduced but it is not zero. To establish a real chloride barrier a water repellent zone as established in specimens type G600 is necessary [4]. The remaining water in samples type G100 and G400 is sufficient to transport a reduced amount of chloride through the barrier. Chloride penetration is slowed down but not prevented. For this reason deep impregnation is required according to recommendations [5-9] if an effective chloride barrier is to be established in concrete.

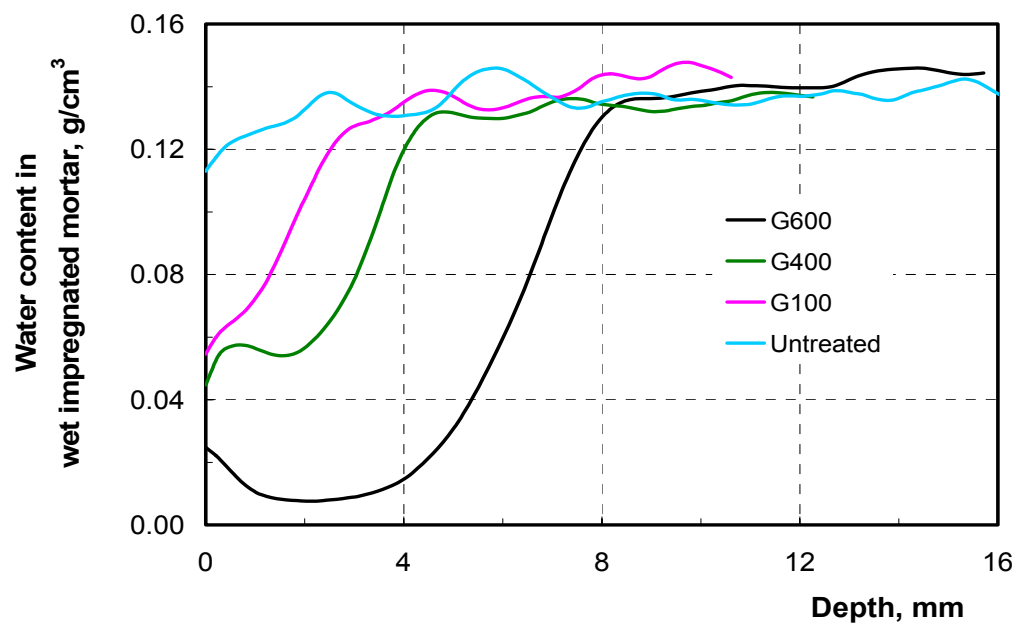

Figure 5: Water content in surface impregnated and water saturated mortar specimens G100, G400 and G600. For comparison the water distribution in untreated mortar is also shown. 


\section{Conclusions}

Based on the results presented in this contribution it can be concluded that:

(1) Water repellent surface layers with a thickness below $5 \mathrm{~mm}$ still contain a certain amount of water if placed in direct contact with water. Chloride can be transported through the still existing water bridges. Chloride ingress into the pore space is slowed down but not prevented.

(2) To prevent chloride penetration into concrete, deep impregnation with silane is necessary. A minimum thickness of the water repellent surface layer of $6 \mathrm{~mm}$ must be achieved.

(3) After water repellent surface treatment a strict quality control must make sure that the minimum thickness of the water repellent layer has been achieved.

\section{Acknowledgment}

The authors gratefully mention that STO, Germany, has provided them with silane gel. In addition the authors gratefully acknowledge the substantial support of ongoing projects by National Natural Science Foundation of China (nos. 51278260 and 51008165), Collaborative Innovation Center of Engineering Construction and Safety in Shandong Blue Economic Zone and National Basic Research Program of China (no. 2009CB623203).

\section{References}

1. H. Pleinert, Determination of Moisture Distributions in Porous Building Materials Neutron Signal Transfer Analysis, Building Materials Reports No. 10, Aedificatio Publishers Freiburg (1998).

2. H. Pleinert, H. Sadouki and F. H. Wittmann, Determination of Moisture Distributions in Porous Building Materials by Neutron Transmission Analysis, Materials and Structures 31 (1998) 218-224.

3. F. H. Wittmann, P. Zhang and T. Zhao, Damage of Concrete under Combined Actions, Restoration of Buildings and Monuments, 17 (2011) 321-330.

4. H. Zhan, F. H. Wittmann and T. Zhao, Relation between the Silicon Resin Profiles in Water Repellent Treated Concrete and the Effectiveness as a Chloride Barrier, Restoration of Buildings and Monuments 11 (2005) 35-46.
5. S. J. Meier and F. H. Wittmann, Water Repellent Surface Impregnation of Concrete: Guidelines and Recommendations, in Basic Research on Concrete and Applications, Proc. ASMES Int. Workshop, F. H. Wittmann and O. Mercier, editors, Aedificatio Publishers Freiburg, Germany (2011) 49-66.

6. S. J. Meier and F. H. Wittmann, Hydrophobieren von Betonoberflächen - Empfehlungen für Planung und Applikation; Traitement hydrofuge de la surface des structures en béton - Recommendations pour la planification et l'execution, Swiss Federal Office for Roads, ASTRA Report No. 591 (2005).

7. S. J. Meier, Grundlagen und Möglichkeiten einer Hydrophobierung von Betonbauteilen, Building Materials Reports No. 21, Aedificatio Publishers Freiburg (2003).

8. A. Gerdes and F. H. Wittmann, Hydrophobieren von Stahlbeton, Teil 1: Transport und chemische Reaktionen silicium-organischer Verbindungen in der Betonrandzone, Restoration of Buildings and Monuments 9 (2003) 41-64.

9. A. Gerdes and F. H. Wittmann, Hydrophobieren von Stahlbeton, Teil 2: Ausführung einer Hydrophobierung - Voruntersuchung, Durchführung und Qualitätssicherung, Restoration of Buildings and Monuments 9 (2003) 117-138.

Received March 17, 2014 